\title{
A ESCALADA DO FASCISMO NO BRASIL: REBATIMENTOS AO CAMPO PROFISSIONAL DA PSICOLOGIA
}

THE RISE OF FASCISM IN BRAZIL: REPERCUSSIONS ONTO THE PROFESSIONAL FIELD OF PSYCHOLOGY

\section{LA ESCALADA DEL FASCISMO EN BRASIL: REPERCUSIONES EN EL CAMPO PROFESIONAL DE LA PSICOLOGÍA}

\author{
Candida Maria Bezerra Dantas* \\ Matheus Rios Silva Santos** \\ Magda Dimenstein ${ }^{* * *}$ \\ João Paulo Macedo ${ }^{* * * *}$
}

\begin{abstract}
RESUMO
Este trabalho objetiva problematizar a escalada do fascismo e do conservadorismo no Brasil e as principais formas de enfrentamento construídas pelo Conselho Federal de Psicologia (CFP). Desde 2016, acompanhamos no país um aumento significativo de discursos conservadores e de ações que cerceiam as liberdades democráticas individuais e coletivas, que nos remetem ao fascismo. A Psicologia, como ciência e profissão, tem sido um dos alvos prioritários dessa onda conservadora. Diante disso, foi realizado um levantamento das notícias hospedadas no site virtual do Conselho Federal de Psicologia, que compreendeu o período de janeiro de 2016 a maio de 2019. Os resultados revelaram importantes consideraçôes sobre a postura do CFP diante do desmonte das políticas públicas, dos retrocessos no campo dos direitos sociais e civis e das manifestações de preconceito, racismo, LGBTfobia ocorridas no país, nos últimos anos.
\end{abstract}

Palavras-chave: Fascismo. Conservadorismo. Democracia. Conselho Federal de Psicologia.

\footnotetext{
"Pós-doutora pela Universidade Federal do Ceará (UFC), Doutora em Psicologia Social, mestra e graduada em Psicologia pela UFRN, professora do Departamento de Psicologia e membro do Programa de Pós-Graduação em Psicologia da UFRN. Tem experiência acadêmica e em pesquisa em Psicologia, atuando principalmente nos seguintes temas: relações de gênero, contextos de vulnerabilidade e políticas públicas. E-mail: candida.dantas@gmail.com

** Graduado em Psicologia pela Universidade Estadual de Feira de Santana (UEFS), mestrando no Programa de Pós-Graduação em Psicologia da UFRN, no qual desenvolve pesquisas nas temáticas de população em situação de rua, movimentos sociais e decolonialidade.E-mail: matheusrssantos@gmail.com

** Professora visitante da UFC, professora titular no Programa de Pós-Graduação em Psicologia da UFRN, bolsista PQ 1A/ CNPq, membro do Comitê Assessor do CNPQ. Atua na área de Saúde Coletiva com ênfase em saúde mental, atenção primária e atenção psicossocial em contextos urbanos e rurais. E-mail: mgdimenstein@gmail.com

**** Docente do Departamento de Psicologia e do Programa de Pós-Graduação em Psicologia da Universidade Federal do Delta do Parnaíba (UFDPa), bolsista PQ-2/CNPq. Atua na área de Saúde Coletiva com ênfase em saúde mental e políticas públicas. E-mail:jpmacedo@ufpi.edu.br
} 


\section{ABSTRACT}

This paper aims to discuss the rise of fascism and conservationism in Brazil and the main ways of confrontation built by the Federal Council of Psychology (CFP). Since 2016, we have been following a significant increase in conservative speeches and actions that curtail individual and collective democratic freedoms, which lead us to fascism. Psychology, as a science and profession, has been one of the priority targets of this conservative wave. Thus, a survey of the news hosted on the website of the Federal Council of Psychology was carried out from January 2016 to May 2019. The results revealed important considerations about the Council's attitude concerning the dismantling of public policies, the setbacks in the field of social and civil rights and manifestations of prejudice, racism and LGBTphobia that have occurred in the country in recent years.

Keywords: Fascism. Conservativism. Democracy. Federal Council of Psychology.

\section{RESUMEN}

Este artículo tiene como objetivo discutir la escalada del fascismo y el conservadurismo en Brasil y las principales formas de confrontación construidas por el Consejo Federal de Psicología (CFP). Desde 2016, hemos estado siguiendo un aumento significativo en discursos conservadores, y prácticas y acciones que limitan las libertades democráticas individuales y colectivas, que nos llevan al fascismo. La psicología, como ciencia y profesión, ha sido uno de los objetivos prioritarios de esta ola conservadora. Ante esto, se realizó una encuesta de las noticias alojadas en el sitio web del Consejo Federal de Psicología, que comprendió el período de enero de 2016 a mayo de 2019. Los resultados revelaron consideraciones importantes sobre la actitud del Consejo hacia el desmantelamiento de las políticas públicas, los reveses en el campo de los derechos sociales y civiles y las manifestaciones de prejuicios, racismo, LGBT que han ocurrido en el país en los últimos años.

Palabras clave: Fascismo. Conservadurismo. Democracia. Consejo Federal de Psicología. 


\section{INTRODUÇÃO}

Psicologia, como ciência e profissão, tem sido um dos alvos prioritários $A$ da onda conservadora que vem assolando o País. Nas últimas décadas, Lé inegável que, de forma hegemônica, nossa categoria é importante protagonista na defesa da democracia e de um projeto de sociedade menos desigual e injusto. Ampliamos o escopo de nossas preocupações e críticas à nossa vocação histórica de tomar o social como investimento normalizador, isto é, nossa tendência à psicologização das realidades sociais, à patologização da vida cotidiana, à medicalização das diferenças e em atender aos padrões hegemônicos de normalidade. Esse alinhamento da Psicologia às pautas democráticas tem gerado, consequentemente, inúmeras disputas e enfrentamentos pela categoria na atualidade, e internamente. A Psicologia é um campo de saber e de práticas muito desejado pelas capturas e adesões que podem operar em relação ao projeto societário retrógrado e ultraconservador que está em curso no País.

Em razão disso, este texto objetiva problematizar a escalada do fascismo e do conservadorismo no Brasil e suas implicações para as práticas profissionais em Psicologia, bem como as principais formas de enfrentamento construídas pelo Conselho Federal de Psicologia (CFP), desde o golpe midiático-políticojurídico de 2016 (Dias, 2018). Para tanto, foi realizado um levantamento das notícias hospedadas no site virtual do CFP, no período de janeiro de 2016 a maio de 2019. Foram selecionadas 301 notícias relacionadas às seguintes temáticas: violação de direitos, processos políticos, políticas públicas, debates ou ações em torno de populações minoritárias, as quais guardam relação direta com o posicionamento político assumido pelo CFP nas últimas décadas. Todas as notícias selecionadas foram lidas na íntegra para verificar o grau de proximidade destas com as temáticas anteriormente elencadas e, posteriormente, organizadas nas seguintes categorias: diversidade sexual e relações de gênero, relações étnicoraciais, criança e adolescentes, Psicologia cristã, saúde mental, políticas públicas, conjuntura política e direitos humanos.

Com base nisso, organizamos o texto em duas partes. Na primeira, faremos uma conceituação geral sobre o fascismo, apresentando como ele se insere nas práticas cotidianas. Além disso, levantaremos alguns elementos que propiciaram a ascensão da extrema direita no Brasil e suas expressões no cenário político atual, no qual presenciamos o avanço do autoritarismo e conservadorismo. Em seguida, discutiremos o campo da Psicologia e suas entidades representativas em articulação com os processos políticos no País, finalizando com o levantamento das notícias veiculadas na página do CFP, na perspectiva de evidenciar as condições 
de emergência dos enfrentamentos e os sucessivos ataques que a Psicologia tem sofrido por seus posicionamentos na defesa da Democracia brasileira, do Estado de direito, dos Direitos Humanos, da manutenção e avanço das políticas sociais e o respeito à diversidade e à diferença.

\section{O GOLPE DE 2016: PAUTA CONSERVADORA E A ESCALADA DO FASCISMO NO BRASIL}

O Brasil entrou, nos últimos anos, para a lista de países que estão enfrentando o processo de autocratização. Este processo é definido pelo V-Dem Institute como qualquer piora substancial ou significativa na escala da democracia liberal de um país. Em nosso caso, fatores como a polarização tóxica na esfera pública, a utilização de discurso de ódio por lideranças políticas, a deterioração dos sistemas de proteção/seguridade social, o desmonte de instâncias de participação e deliberação popular, e a disseminação em massa de campanhas de desinformação on-line (fake news) tiveram peso substancial em nossa imagem perante o mundo como um país em vertiginosa erosão democrática (V-Dem Institute, 2019).

A ascensão e a chegada ao poder de uma extrema direita que recorre ao uso de uma retórica explicitamente fascista e ultraconservadora configuramse como elementos decisivos dessa erosão. Desse modo, analisar a conjuntura histórica, social e política que propiciaram o atual cenário está na tarefa do dia das forças pró-democracia. Uma vez que ataques indiscriminados à produção de conhecimento, a setores da sociedade e a instâncias democráticas são realizados constantemente por agentes públicos e movimentos organizados da direita no Brasil, convém lançarmos as mesmas perguntas de Bertolt Brecht, apresentadas no prefácio escrito por Iasi, no livro Introdução ao fascismo, de Konder (2009): "Por que temem tanto a palavra clara? Que força têm certas palavras que podem implodir as mais sólidas fortalezas?” (p. 9).

Passados pouco mais de 25 anos desde o fim do período ditatorial institucionalizado no Brasil, o País se defronta novamente com um cenário de ruptura democrática e social, a partir do impeachment da presidenta, então eleita, Dilma Rousseff, Partido dos trabalhadores (PT). O golpe de 2016 segue a tendência de outros golpes na cena contemporânea de países da América Latina, com alianças espúrias entre o capitalismo financeiro, neoliberalismo e neoconservadorismo de caráter classista, machista e racista. Segundo Rolnik (2018), tal aliança procura garantir as condições necessárias para a instalação de um Estado neoliberal, em que é necessário "destruir todas as conquistas democráticas e republicanas, dissolver seu imaginário e erradicar de cena seus 
protagonistas - entre os quais, prioritariamente, as esquerdas em todas as matizes" (p. 148).

Por esse aspecto, é possível afirmar que está em curso uma onda conservadora como reação transnacional e globalizada diante de alguns acontecimentos políticos ocorridos nas duas últimas décadas em torno:

a) da ascensão do multiculturalismo e lutas para o reconhecimento e acesso de direitos das minorias sociais às políticas de bem-estar, à segurança de cidadania e políticas de equidade;

b) da emergência do problema dos movimentos migratórios internacionais em direção aos países do Norte e a polarização de debates/açôes em torno de políticas para acolhida/integração ou de antagonização e securitização da imigração, combustível para xenofobia e o racismo contemporâneos;

c) dos ataques terroristas em importantes cidades dos países do Norte, abrindo debates sobre poderes discricionários, instituindo estados de guerra e medidas de exceção;

d) dos graves efeitos da crise financeira de 2008, com o encolhimento da economia, desemprego, perda da capacidade regulatória do Estado e adoção de medidas de austeridade econômica; e

e) da eclosão de movimentos contestatórios, como a Primavera Árabe, Movimento Occupy, Movimento dos Indignados, entre outros (Burity, 2018).

Tais tensões produziram acirramentos, descompassos entre demandas por direitos, polarização política, inseguranças e políticas de medo, acenando para um novo establishment econômico, político e estético, ancorados: na radicalização das ações de mundialização do capital; na desregulamentação e controle financeiro do Estado; em ações sistemáticas de desqualificação da política; no trabalho precário como regra; na afirmação de um processo civilizatório orientado por valores do livre mercado, da justiça do mercado, do individualismo autônomo e empreendedor; na aceleração no ritmo das mudanças sociais e formas de identidade; na precarização da vida; e na circulação e legitimação de ideias xenofóbicas, sexistas, homofóbicas e racistas (Hobsbawm, 2007; Harvey, 2012; Antunes, 2018). 
No cenário brasileiro, a disputa pela hegemonia política no País passou a redesenhar a conformação das forças políticas e sociais que foram agudizadas por acontecimentos como:

a) as chamadas "Jornadas de Junho de 2013", em que explodiram as manifestações de rua e reuniram o inconformismo com a situação macropolítica do País, em um movimento disperso e heterogêneo contra as instituições, em suas mais diferentes expressões;

b) a retomada da agenda anticorrupção em torno da investigação de um determinado grupo político, com um alto grau de contradição e incendiada, de forma efusiva, pela grande mídia nacional;

c) os limites da governabilidade do governo do PT diante da política de coalisão com um Congresso Nacional abertamente fisiologista e obstacularizador das ações governistas;

d) a adoção de políticas anticíclicas como antídoto pouco efetivo para a saída da crise econômica em 2013, acompanhada de políticas de austeridade fiscal, cortes e distanciamento das expectativas de diversos setores da sociedade (Burity, 2018).

Tais fatores, como afirma Rolnik (2018), foram vetores impulsionadores para a produção subjetiva e desejante de diversos setores e classes sociais brasileiras, com efeitos micropolíticos em direção a uma crescente "demonização" dos líderes à esquerda, aglutinando desejos antipetistas e a identificação da corrupção com tudo aquilo que é da ordem da coisa pública e estatal. Esse conjunto de fatores ajudaram a "preparar o terreno [não apenas] para o golpe, [mas] para a propagação da insegurança e do medo de colapso" (Rolnik, 2018, p. 160), para o apoio necessário às contrarreformas do governo Temer, Movimento Democrático Brasileiro (MDB), a exemplo da reforma trabalhista e aprovação da Proposta de Emenda à Constituição (PEC) dos gastos públicos; para a eleição do presidente Jair Bolsonaro Partido Social Liberal (PSL) e de um Congresso Nacional ainda mais conservador, fortalecendo as bancadas da "bala, do boi e da Bíblia" e da direita fisiologista; e para a continuidade de contrarreformas como a da Previdência.

Ainda para autora, todo esse cenário constitui-se como território, espécie de platô, mais que necessário para o que denomina de "surto conservador", em que o renascimento da "moral igrejista, familista e identitária" (Rolnik, 2018, p. 166) apoia ataques violentos contra as minorias e militarização da vida tanto no nível 
macropolítico das instituições quanto na micropolítica, ao alimentar discursos, práticas de ódio e violências que atravessam, de modo mais explícito, o cotidiano das relações.

Assim, acompanhamos o aumento significativo de discursos, práticas e ações que cerceiam as liberdades e posicionamentos individuais e de instituiçóes, movimentos que historicamente nos remetem ao fascismo (Garcez, Martins, Guilherme, \& Batista, 2019).

Tomar o fascismo como um movimento fundamental para as articulações entre os neoconservadorismos e a intensificação do neoliberalismo no cenário atual do país é linha condutora de nossa argumentação. Konder (2009) nos alerta que a palavra "fascismo" contém um alto teor explosivo, ao mesmo tempo em que é um tema escorregadio de compreensão e conceituação difícil, o qual, muitas vezes, banaliza e descaracteriza seu uso. Diante disso, é um desafio capturar conceitualmente distintos movimentos históricos influenciados por uma série de especificidades sociais e culturais. Nesse sentido, Paxton (2007) lembra que o fascismo deve ser "analisado em ação, desde seus primórdios até o cataclismo final, no interior da complexa teia de interações com a sociedade por ele formada” (p. 47). Assim, é indispensável resgatar o termo do mau uso.

Konder (2009), ao revisitar historicamente o termo "fascismo", lançado por Mussolini, aponta como seus elementos característicos a união em torno de um líder central e a manipulação, por parte desse líder, das massas populares. Essa manipulação recorre a sentimentos de ódio, raiva e decepção, e são direcionadas para a luta e o combate a um tipo de inimigo comum à nação, à ordem pública e, ou, ao Estado.

Além desses dois elementos, Eco (1995) elenca algumas características que são típicas do fascismo clássico:

a) culto à tradição, o qual, muitas vezes, pode surgir como uma forma de nacionalismo, chauvinismo;

b) rejeição do modernismo;

c) apego ao irracionalismo;

d) aversão à discordância, uma vez que esta é compreendida como traição ou deslealdade;

e) busca incessante pelo consenso, por meio da exacerbação do medo pela diferença; 
f) postura de guerra permanente, seja contra os judeus, os comunistas ou, mais recentemente, os petistas;

g) desprezo e deslegitimação dos espaços democráticos de representatividade;

h) deriva do medo, frustração individual ou social;

i) o líder é considerado um intérprete da vontade comum dos seus seguidores, por isso a manipulação das massas através do populismo.

Como é notório, passamos a conviver, no Brasil, de forma mais acintosa, com lideranças políticas e administrativas de cargos públicos que recorrem constantemente a muitos desses aspectos no dia a dia. Não à toa, Paxton (2007) faz questão de nos lembrar que o fascismo está presente em quase todos os países democráticos atualmente e é contundente ao alertar que, para se enraizar em determinada sociedade, o fascismo não precisa de uma "marcha" de dimensões espetaculares, mas a tolerância ao tratamento ilegal de supostos inimigos nacionais já é suficiente para gerar o ambiente propício para tal infestação.

Foucault (1993), na introdução à obra O Anti-Édipo de Deleuze e Guattari, brinda-nos com uma pequena análise sobre os microfascismos cotidianos ao considerar, para além das experiências históricas de Hitler e Mussolini, "também o fascismo que está em todos nós, que ronda nossos espíritos e nossas condutas cotidianas, o fascismo que nos faz gostar do poder, desejar essa coisa mesma que nos domina e explora” (p. 197). Nesse sentido, o fascismo é pensado como uma estratégia, uma tecnologia, uma lógica para além das instituições formais, mas opera também ao nível molecular. Haveria, assim, um processo de desterritorialização dos processos fascistas molares e a emergência dos microfascismos que se expressam no cotidiano por meio do ódio pelo diferente (Hur, 2018).

A radicalização desses discursos deve ser analisada também a partir do neoconservadorismo que surge como reação ao Estado de bem-estar social, à contracultura e à chamada nova esquerda (Almeida, 2018). De acordo com esse pensamento, o mundo estaria passando por uma "infestação" de sindicalistas, estudantes, comunistas, negros e feministas; grupos que ganham força por causa da permissividade e do assistencialismo estatal, portanto seria necessária a restauração da autoridade, o estabelecimento da ordem e a implantação de um Estado mínimo.

Com a ascensão dos governos democráticos do Brasil, especialmente a partir de 2003, com a primeira eleição do presidente Luís Inácio Lula da 
Silva, foi elaborado, em nosso País, um plano (entendido como um recorte no infinito de possibilidades) que, seguramente, foi muito potente para frear esse conjunto de forças conservadoras e para nos lançar às forças da multiplicidade e da heterogeneidade, forças constitutivas da esfera pública e aliadas ao desenvolvimento de um projeto societário que buscava assegurar a democracia tanto como forma de governo quanto de possibilidade de multiversos com diferentes racionalidades, ontologias, epistemologias.

A Democracia e a Constituição Federal de 1988 interpelaram a Psicologia; tocaram nos seus cárceres por meio das políticas públicas inclusivas, de nossa inserção nessas políticas, da entrada da diferença, de outros corpos, de outras vidas na cena cotidiana da profissão. Em razão disso, foi sendo gestado outro compromisso ético-político, não sem embates e obstáculos, na direção de uma Psicologia alinhada a um projeto societário de cunho democrático, sustentado pelos ideais de justiça social, equidade, solidariedade e universalidade de direitos. É sobre esse movimento e os rebatimentos atuais em torno da categoria profissional que discutiremos a seguir.

\section{A PSICOLOGIA E A CONSTITUIÇÃO DE UM COMPROMISSO ÉTICO-POLÍTICO PARA A PROFISSÃO: RESISTÊNCIAS E ENFRENTAMENTOS CONTEMPORÂNEOS-}

Ao revisitarmos os estudos sobre a história da Psicologia, como ciência e profissão no Brasil, é evidente a intrínseca relação com o desenvolvimento do Estado capitalista brasileiro. Com o processo de modernização, especialmente a partir do incremento da industrialização, na década de 1930, os conhecimentos e práticas psicológicas focaram sua atenção no homem moderno e urbano, com capacidade de vender sua força de trabalho ao capital nascente, restando aos "inúteis" da sociedade as teorias disciplinadoras e patologizantes que serviam à manutenção da ordem social. Como dizem Prado Filho e Trisotto (2007), a partir de uma leitura foucaultiana, a Psicologia, por seu caráter disciplinar constitutivo e associado às práticas de normalização social, foi definida criticamente por Foucault como "disciplina da norma" (p. 1). Isso significa que, sob o manto da neutralidade, esse campo se constituiu como instrumento de dominação e disciplinarização dos corpos (Hur, 2012) para forjá-los sob os marcos da sociabilidade burguesa e submetê-los à dinâmica de produção e exploração capitalista.

Foi por meio da aliança com os interesses das elites brasileiras que a profissão foi regulamentada e oficialmente reconhecida pelo Estado, com a Lei Federal n. ${ }^{\circ}$ 4.119, de 27 de agosto de 1962, às portas do golpe civil-militar de 1964, 
período dramático da história do País, marcado pelo cerceamento dos direitos civis, políticos e sociais, absoluta centralização decisória, fragmentação do aparelho de Estado em inúmeros segmentos autônomos e acentuada tendência à privatização.

Apesar da indicação de criação de órgãos de fiscalização da profissão, presente na lei de regulamentação da profissão, o CFP foi criado no início da década de 1970 como autarquia pública e com autonomia financeira e administrativa, com o objetivo de regulamentar, orientar e fiscalizar o exercício profissional, em um momento de perseguição violenta aos movimentos sociais, em razão do Ato Institucional n. ${ }^{\circ} 5$ (A.I. 5) (Hur, 2012). É somente a partir da década de 1980, com o processo de redemocratização no País, que o CFP quebra o padrão de atuação estritamente burocrático e fiscalizador e começa a protagonizar embates relacionados ao contexto social e político brasileiro, posicionando-se gradativamente em favor das lutas sociais, da democracia e dos direitos humanos. Esse processo culmina na construção de um discurso de "compromisso social" da profissão, forjado na década de 1990 (Hur \& Lacerda Júnior, 2017).

A Constituição Cidadã de 1988 foi um marco na geração de uma nova política pública em relação à saúde, assistência social e educação, entre outros direitos. A partir disso, um contingente significativo de profissionais da Psicologia passou a trabalhar no âmbito das políticas públicas, as quais foram se consolidando ao longo do tempo, como campo de atuação privilegiado da profissão. O Sistema Conselhos, na tentativa de construir espaços de reflexão sobre os desafios da prática profissional nesse campo, fez um forte investimento em eventos, publicações e pesquisas com foco em temáticas como "saúde, direitos das crianças e adolescentes, direitos do idoso, direitos da mulher, da família, medicalização da sociedade e da educação, antimanicomialismo, saúde do trabalhador, direito à política, direito à cidadania, entre outros" (Furlan, 2017, p. 96). No âmbito federal, houve a criação pelo CFP do Centro de Referência Técnica em Psicologia e Políticas Públicas (Crepop, 2006), com o objetivo de consolidar a produção de referências para a atuação de psicólogas e psicólogos nos mais diferentes setores, voltadas às populações em situação de vulnerabilidade social.

É evidente que esse campo profissional é permeado de contradições e lutas internas. A Psicologia é marcada por uma diversidade teórica e epistemológica, por diferentes visões de mundo e posições políticas que norteiam a produção de saberes e fazeres. Com base em Rose (2011), consideramos a Psicologia um campo aberto em que coexistem projetos de sociedade diversos que tanto podem estar ancorados em princípios progressistas de justiça social quanto em projetos conservadores e fascistas. No bojo dessa onda conservadora, como referimos 
anteriormente, a posição política do CFP em defesa de uma sociedade justa, democrática e igualitária, seja no processo de normatização da profissão, seja no campo das lutas sociais, está no centro do embate de forças que buscam consolidar uma versão tecnicista, apolítica e neutra da profissão, versão que desempenha a função de legitimação das relações de dominação e justificação da ordem estabelecida, por meio de seus agentes, considerados, de acordo com Coimbra (1995), como os "guardiōes da ordem". Dessa maneira, destacaremos, a partir desse ponto, o posicionamento do CFP, principal entidade representativa no País, diante dos acontecimentos políticos da atualidade, o qual revela a disputa discursiva em torno de temas que impactam na vida cotidiana e nos modos de vida da população brasileira.

\subsection{O posicionamento político do CFP diante da conjuntura política de 2016-2019: resistências em operação}

Tomando como base o levantamento realizado no período de janeiro de 2016 a maio de 2019 no site de notícias do CFP, podemos tecer algumas considerações sobre a postura do Conselho diante do desmonte das políticas públicas, dos retrocessos no campo dos direitos sociais e civis, e manifestações de preconceito, racismo, lésbicas, gays, bissexuais, travestis e transsexuais (LGBTfobia) ocorridas no País nos últimos anos. A apresentação dos resultados do levantamento será realizada em dois eixos: o primeiro voltado aos discursos e pautas conservadoras, que engloba temas como diversidade sexual, relações de gênero e direitos das mulheres, crianças e adolescentes, relações étnico-raciais e Psicologia cristã. O segundo eixo tem relação com os retrocessos no campo dos direitos e desmonte das políticas públicas, e concentra temas como saúde mental, políticas públicas, conjuntura política e direitos humanos.

\subsubsection{Eixo I: Discursos e pautas conservadoras}

\subsubsection{Diversidade sexual e relaçôes de gênero}

O tema da diversidade sexual e relações de gênero teve a maior taxa de frequência, com 91 notícias do total das selecionadas. A partir de 2016, verificamos um acirramento dos posicionamentos do CFP manifestados por meio de notas de repúdio, notas de apoio, realização de entrevistas, evocação de datas comemorativas. Diante da ascensão do conservadorismo que se arraiga em valores morais baseados na heteronormatividade e na concepção de que só existe uma forma de experienciar a sexualidade (relação binária homem-mulher 
cis), as pessoas lésbicas, gays, bissexuais, transgénero, queer ou questionadores e intersexo (LGBTQI+) constituem umas das populações que mais tiveram suas liberdades individuais e direitos civis tolhidos. As notícias estão relacionadas aos direitos da população LGBTQI+, à discussão sobre a despatologização de outras formas de sexualidade e de identidade, ao debate em torno do papel de psicólogas e psicólogos e da "cura gay" e, especialmente, à defesa das Resoluçôes 01/1999 e 01/2018. A primeira veta ao(à) profissional a realização de qualquer ação que favoreça a patologização de comportamentos ou práticas homoeróticas, ou ação coercitiva tendente a orientar homossexuais para tratamentos não solicitados (Resolução CFP n. ${ }^{\circ} 1 / 1999$ ), e a segunda direciona os conhecimentos e práticas psicológicas para a eliminação da transfobia e do preconceito em relação às pessoas transexuais e travestis (Resolução CFP n. ${ }^{\circ} 1 / 2018$ ).

Em março de 2016, um dos conselheiros do CFP alertou para a articulação de setores da sociedade para derrubar essas resoluções que impedem psicólogas e psicólogos de proporem tratamento ou cura em relação à diversidade sexual. Ao longo desse ano, travou-se uma batalha judicial em torno de uma ação popular de um grupo de profissionais que defendia os tratamentos curativos para pessoas LGBTQI+. A ação foi extinta em abril de 2019 pelo Supremo Tribunal Federal (Conselho Federal de Psicologia, 2019b). Em maio de 2016, o CFP divulgou importante decisão da Organização Mundial de Saúde (OMS), na qual a transexualidade saía, depois de 28 anos, da categoria de transtornos mentais para integrar o de "condições relacionadas à saúde sexual". Essa decisão teve implicações diretas de ratificação de ambas as resoluções bem como demonstrou o inequívoco posicionamento do Conselho em lutar por garantir a autonomia de a pessoa viver sua identidade de gênero, fosse ela a hegemônica ou relacionada às minorias sexuais.

O CFP também marcou posicionamento diante dos direitos sexuais e reprodutivos das mulheres bem como à sua integridade física, psicológica e moral. É o que constatamos pela análise de 30 das 91 notícias que abordavam questóes como aborto, violência contra as mulheres e direitos das mulheres. Quanto ao tema do aborto, o posicionamento do CFP se baseou em nota técnica de 2014, que salientava "a decisão de ter filhos compete a quem vai gestá-los e criá-los e não ao Estado. Consideramos que não há como assegurar a promoção dos direitos sexuais e reprodutivos sem o acesso ao aborto legal e seguro" (Conselho Federal de Psicologia, 2016a).

O CFP ainda defendeu que, com a legalização, psicólogas e psicólogos poderiam ajudar a mulher a tomar a melhor decisão para a vida dela, entendendo que ela tinha o direito de decidir pela continuidade da gestação ou não. A preocupação do CFP também se voltou para o acolhimento, acompanhamento 
e tratamento de mulheres vítimas de violências. Nesse caminho, em matéria de março de 2016, o CFP apontou como um desafio para a categoria "identificar e tratar os transtornos causados por essas violências", além de "fazer com que essas mulheres recebam um acompanhamento clínico adequado" (Conselho Federal de Psicologia, 2016b). A fim de dar suporte aos profissionais de Psicologia, o CFP produziu materiais audiovisuais, assinou documentos (como o da regulamentação do sigilo em caso de violência doméstica), realizou debates sobre o tema bem como fez parte de comissão ligada ao Conselho Nacional de Saúde (Conselho Federal de Psicologia, 2017a).

\subsubsection{Relaçôes étnico-raciais}

Outro campo de disputas importante diz respeito à vida, saúde e integridade de populações minoritárias que foram subalternizadas ao longo do processo histórico do Brasil. Assim, foi possível identificar 31 notícias que tinham relação com o tema relaçóes étnico-raciais. Entre as categorias, despontam a de povos indígenas, povos quilombolas e a de combate ao racismo. Quanto aos povos quilombolas, as notícias mais presentes estavam relacionadas à demarcação de territórios ou à manutenção das comunidades, em contraposição a um movimento de setores conservadores que tentaram derrubar o Decreto 4.887/2003, que regulamenta a demarcação e titulação das terras ocupadas (Conselho Federal de Psicologia, 2017 d). O combate ao racismo também deu a tônica das notícias por meio da percepção de que o racismo ainda estava fortemente presente nos modos de atuação de psicólogas e psicólogos, devido ao racismo estrutural que organiza o Estado brasileiro e nosso padrão societário. Como estratégia de enfrentamento a esse crime discriminatório, o CFP fomentou a articulação de psicólogas e psicólogos negras e negros na luta antirracista.

\subsubsection{Crianças e adolescentes}

O avanço do conservadorismo no Brasil veio acompanhado de uma ânsia punitiva de setores da sociedade que passaram a vislumbrar, na redução da maioridade penal, uma medida eficaz para a questão da segurança pública. Aliado à redução da maioridade penal, o trabalho infantil, o abuso sexual e a inclusão de adolescentes no sistema socioeducativo e no Sistema Único de Segurança Pública (SUSP) foram questôes que apareceram em relação às crianças e adolescentes, que resultou em 24 notícias. Diante da tentativa conservadora de criminalização da juventude brasileira, o CFP destacou os seguintes argumentos contrários: não resolve a questão ou o problema, ataca o indivíduo, desconsidera 
as causas da violência, da criminalidade e do envolvimento de adolescentes com atos infracionais; é uma resposta irracional a um apelo da sociedade; carrega o perigo de criminalização da adolescência; inclui adolescentes num sistema penal falido, em um lugar que produz mais miséria humana e criminalidade.

No que diz respeito às tentativas de desmonte do Estatuto da Criança e do Adolescente e à flexibilização do trabalho infantil (que inclusive ganhou lastro em falas do presidente Jair Bolsonaro), o CFP foi categórico ao manifestar posicionamento no sentido de combater o trabalho infantil "como forma de proteção à infância. Este combate precisa estar em sintonia com diversas políticas públicas, como o acesso e a permanência das crianças na escola, a luta contra a exploração sexual e o tráfico de crianças" (Conselho Federal de Psicologia, 2018c).

\subsubsection{Psicologia cristã}

Apesar de figurar com apenas uma notícia, a Psicologia cristã é um movimento importante que merece destaque por estar intimamente relacionado aos conservadorismos e fundamentalismos religiosos que ressurgiram recentemente no campo profissional, atravessando questóes como os retrocessos propostos no campo da diversidade sexual. A notícia selecionada se refere à criação de cursos de "Psicologia Cristã" no País. O CFP se posicionou, alegando que atentam contra a Constituição Federal e o Código de Ética, e que não estão rol das 12 especialidades validadas técnica e cientificamente.

\subsubsection{Eixo II: Retrocessos no campo dos direitos e desmonte das políticas públicas}

\subsubsection{Saúde mental}

A saúde mental e a Reforma Psiquiátrica são temas de maior interesse da Psicologia. A partir da análise das 50 notícias nesse tema, percebemos a posição do CFP contra o fortalecimento da lógica manicomial, a retração da rede de serviços socioassistenciais, o aumento de comunidades terapêuticas e a perda de vagas de trabalho por conta do desmonte das políticas de saúde mental no País e dos retrocessos visíveis nos últimos anos. A nomeação de Valencius Wurch Duarte Filho para a Coordenação Nacional de Saúde Mental, em dezembro de 2015, foi duramente criticada pelo CFP e considerada uma ruptura na sequência de gestôes públicas comprometidas com a Reforma Psiquiátrica (Conselho Federal de Psicologia, 2017a). O CFP demarcou posição inequívoca contra a expansão 
das comunidades terapêuticas no Brasil a partir da divulgação do relatório de inspeção em 2018, que concluiu que muitas delas adotam práticas de violação dos direitos humanos, tais como não dispor de laudo médico para internação, práticas de castigo e punição a internos, além de não respeitarem a diversidade de orientação sexual e a identidade de gênero (Conselho Federal de Psicologia, 2018c).

\subsubsection{Direitos humanos}

Em 10 de dezembro de 2018, o CFP comemorou os 70 anos da Declaração Universal dos Direitos Humanos. Ao fazer um resgate histórico das atrocidades do nazismo, o CFP fez questão de lembrar que "o que iniciara como a defesa da pátria e de Deus, o combate ao comunismo e o culto ao militarismo, terminou como uma impensável escalada de ódio, de intolerância e violência, culminando no genocídio de populações inteiras" (Conselho Federal de Psicologia, 2018e). Entre as 32 notícias identificadas, foi possível observar questôes relativas à violência policial, combate à tortura, violência no campo, população em situação de rua e violência contra ativistas. A nota de pesar em relação à execução da vereadora Marielle Franco, defensora das populações minoritárias e dos direitos humanos, e o motorista Anderson Gomes, em março de 2018, no Rio de Janeiro é emblemática (Conselho Federal de Psicologia, 2018a).

\subsubsection{Políticas públicas}

"O cenário brasileiro necessita de posicionamentos institucionais diante do desmonte de políticas públicas" (Conselho Federal de Psicologia, 2017c). Esse foi o entendimento dos conselheiros do Crepop, em notícia veiculada, em março de 2017, pelo site do CFP. Apesar de ser um tema transversal, foi possível sistematizar 27 notícias divulgadas pelo CFP, em que prevalece posicionamento em defesa do Sistema Único de Assistência Social e do Sistema Único de Saúde, assim como a recomendação do Conselho Nacional de Direitos Humanos de suspensão da "Nova Política de Saúde Mental", "que estabelecia a retomada de financiamento dos hospitais psiquiátricos e das comunidades terapêuticas e a compra de equipamentos de Eletroconvulsoterapia (ECT) pelo Sistema Único de Saúde (SUS)" (Conselho Federal de Psicologia, 2019a).

\subsubsection{Conjuntura politica}

O tema conjuntura política registrou 20 notícias, indicando que as últimas gestões do CFP não estiveram alheias a importantes acontecimentos da política 
institucional brasileira. A atuação se deu pela divulgação de cartas, notas e manifestos que expressavam preocupação com o cenário político, de graves ameaças à democracia. Em maio de 2016, o CFP divulga carta assinada pelo Coletivo Iara Iavelberg aos senadores. "O documento faz uma crítica 'aos frágeis fundamentos apresentados pela Câmara de Deputados para autorizar a abertura do processo de impedimento contra a Presidenta Dilma Rousseff" (Conselho Federal de Psicologia, 2016c), denunciando a crise ética e civilizatória que o País tem enfrentado nos últimos anos. Mais recentemente, sobre a escalada do fascismo no Brasil, a Comissão de Direitos Humanos do CFP fez a seguinte manifestação, em março de 2018:

Passamos da intolerância às diferenças e do ódio nas redes sociais para a barbárie. O senso comum que convivia, naturalizava e estimulava o ódio agora passa a aceitar, defender e estimular a barbárie. O Estado de Direito, a democracia e o respeito aos Direitos Humanos parecem conceitos ultrapassados e longínquos. Soma-se a isso os retrocessos nos direitos civis, na legislação sobre uso de drogas lícitas ou ilícitas, na criminalização do aborto, no extermínio de jovens negros moradores das periferias, as balas perdidas, o assassinato de LGBTs, de defensores de Direitos Humanos e a ocupação do exército no estado do Rio Janeiro. Tudo isso nos diz de uma situação que saiu do controle, do convívio social, das regras, das leis, da civilidade. A Comissão de Direitos Humanos do Conselho Federal de Psicologia (CFP), chama as psicólogas e os psicólogos, assim como toda a sociedade, para a reflexão a respeito da crise ética e civilizatória enfrentada pelo Brasil. É preciso resistir e dizer um basta! (Conselho Federal de Psicologia, 2018b)

\section{CONSIDERAÇÕES FINAIS}

Pelos posicionamentos identificados anteriormente, consideramos que o CFP tem se revelado um dispositivo potente de combate ao conservadorismo e ao fascismo em franca ascensão no Brasil atual. Por meio de sua atuação, expressa nos enfrentamentos produzidos nas mais diferentes esferas institucionais, podemos acompanhar os acontecimentos em curso no País fazendo análise do presente e de apreensão de nosso tempo.

O avanço dos discursos conservadores atravessa o campo profissional, com tentativas de minar seus aparatos legais e institucionais, resultados de um processo de politização das suas entidades no enfrentamento das contradiçōes constitutivas do campo da Psicologia, daquilo que habita os porôes da nossa profissão, do que está instituído como lógica ordenadora da vida. Nesse processo, questiona-se a neutralidade política, o tecnicismo, o reducionismo epistêmico e ontológico da ciência e profissão, marcando uma posição inconteste em defesa da justiça, igualdade, da garantia dos processos democráticos, da defesa dos direitos humanos, das minorias e da diversidade e diferença. 
Assim, os enfrentamentos assumidos pelo Conselho escancaram, de um lado, um conjunto de forças que operaram hegemonicamente em nossa sociedade, a moralidade, o colonialismo, a escravidão, forças que são atualizadas no avanço do fascismo e conservadorismo no País, especialmente a partir de 2016, e colocam em risco os avanços democráticos e progressistas que, a duras penas, foram conquistados nas últimas décadas, mesmo sob os marcos do capitalismo. Por outro lado, os embates em curso visibilizam diferentes campos de força em disputa no próprio campo profissional, explicitados, por exemplo, na recente eleição do Sistema Conselhos: uma das chapas representava o movimento da Psicologia Cristã e uma aliança entre o conservadorismo e fundamentalismo religioso que cooptaram nossas instituições democráticas no País, em seus diferentes níveis.

Além disso, acompanhamos, pelas notícias analisadas, o progressivo desmonte do campo das políticas públicas, em consonância com a aderência irrestrita aos preceitos neoliberais que operam, acirrando no cotidiano as biopolíticas contemporâneas de gestão e precarização da vida. Tais políticas induzem a exposição das populações (negros, indígenas, quilombolas, mulheres, populações LGBTQI+, nordestinos, pobres) à violência e a morte (Butler, 2015), a partir de uma série de intervençôes cirurgicamente produzidas que jogam esses sujeitos em zonas de menor visibilidade e de desproteção social, produzindo o que Mbembe (2018) denomina necropolítica, produção de vidas descartáveis, de "mundos de morte" (p. 71), como um empreendimento contemporâneo de subjugação e aniquilamento dos corpos.

Dessa forma, a escalada do fascismo no Brasil tem produzido rebatimentos no campo profissional da Psicologia, forçando a categoria, por meio de seus órgãos representativos, a produzir desvios e desestabilizações em relação às suas bases epistemológicas e técnico-operativas alinhadas ao conservadorismo, instigando a eclosão de forças instituintes e a criação de uma multiplicidade de pontos de resistência, em articulação com movimentos sociais, coletivos de lutas populares, sindicatos, enfim, com o chamado campo progressista do País, cuja capilaridade poderá ter ressonância nos modos instituídos de funcionamento da categoria, especialmente na micropolítica da vida cotidiana, com possibilidade da produção de novos agenciamentos, novas composiçôes e arranjos subjetivos implicados na defesa de projetos societários emancipatórios. 


\section{REFERÊNCIAS}

Almeida, S. L. (2018). Neoconservadorismo e liberalismo. In E. S. Gallego (Org.), O ódio como politica: a reinvenção das direitas no Brasil. (pp. 27-32). São Paulo: Boitempo.

Antunes, R. (2018). O privilégio da servidão: o novo proletariado de serviços na era digital. São Paulo: Boitempo.

Burity, J. A. (2018). A onda conservadora na política brasileira traz o fundamentalismo ao poder? In R. Almeida, \& R. Toniol. (Orgs.), Conservadorismos, fascismos e fundamentalismos. (pp. 15-66). Campinas: EdUnicamp.

Butler, J. (2015). Quadros de guerra: quando a vida é passivel de luto? Rio de Janeiro: Civilização Brasileira.

Coimbra, C. (1995). Guardióes da ordem: uma viagem pelas práticas psi no Brasil do "Milagre". Rio de Janeiro: Oficina do Autor.

Conselho Federal de Psicologia. (2016a, 10 março). Direitos da mulher e o aborto. Brasília: CFP. Recuperado a partir de https://site.cfp.org.br/direitosda-mulher-e-o-aborto/

Conselho Federal de Psicologia. (2016b, 11 março). O adoecimento psíquico pode ser resultado de violências invisibilizadas. Brasília: CFP. Recuperado a partir de https://site.cfp.org.br/o-adoecimento-psiquico-pode-ser-resultado-deviolencias-invisibilizadas/

Conselho Federal de Psicologia. (2016c, 11 maio). Coletivo Iara Iavelberg entrega carta aos senadores. Brasília: CFP. Recuperado a partir de https://site.cfp.org.br/ coletivo-iara-iavelberg-entrega-carta-aos-senadores/

Conselho Federal de Psicologia. (2017a, 4 janeiro). Nem uma a menos. Brasília: CFP. Recuperado a partir de https://site.cfp.org.br/nem-uma-a-menos/

Conselho Federal de Psicologia. (2017b, 23 janeiro). Entrevistados analisam avanços e desafios na Saúde Mental. Brasília: CFP. Recuperado a partir de https:// site.cfp.org.br/entrevistados-analisam-avancos-e-desafios-na-saude-mental/

Conselho Federal de Psicologia. (2017c, 9 maio). Retomada do Crepop faz contraponto ao desmonte de políticas públicas. Brasília: CFP. Recuperado a partir 
de https://site.cfp.org.br/retomada-crepop-faz-contraponto-ao-desmonte-depoliticas-publicas/

Conselho Federal de Psicologia. (2017d, 16 agosto). Processos de terras quilombolas aguardam julgamento no STF. Brasília: CFP. Recuperado a partir de https://site. cfp.org.br/terras-quilombolas-aguardam-julgamento/

Conselho Federal de Psicologia. (2018a, 15 março). Marielle Franco, presente. Brasília: CFP. Recuperado a partir de https://site.cfp.org.br/marielle-francopresente

Conselho Federal de Psicologia. (2018b, 28 março). CDH repudia violência que geram barbárie e ferem a democracia. Brasília: CFP. Recuperado a partir de https://site.cfp.org.br/cdh-repudia-atos-de-violencia-que-geram-barbariee-ferem-a-democracia/

Conselho Federal de Psicologia. (2018c, 12 junho). A Psicologia no combate ao trabalho infantil. Brasília: CFP. Recuperado a partir de https://site.cfp.org.br/ psicologia-no-combate-ao-trabalho-infantil/

Conselho Federal de Psicologia. (2018d, 21 junho). Comunidades terapêuticas violam direitos. Brasília: CFP. Recuperado a partir de https://site.cfp.org. $\mathrm{br} /$ inspecao-em-comunidades-terapeuticas-revela-violacoes-de-direitoshumanos/

Conselho Federal de Psicologia. (2018e, 10 dezembro). Pouco a comemorar, muito a resistir. Brasília: CFP. Recuperado a partir de https://site.cfp.org.br/ pouco-a-comemorar-muito-a-resistir/

Conselho Federal de Psicologia. (2019a, 22 março). CNDH recomenda suspensão de "Nova Política de Saúde Mental". Brasília: CFP. Recuperado a partir de https://site.cfp.org.br/conselho-nacional-de-direitos-humanos-recomendasuspensao-de-nova-politica-de-saude-mental/

Conselho Federal de Psicologia. (2019b, 24 abril). STF concede ao CFP liminar mantendo integra e eficaz a Resolução 01/99. Brasília: CFP. Recuperado a partir de https://site.cfp.org.br/stf-concede-ao-cfp-liminar-mantendo-resolucao-01-99/

Decreto n.o 4.887, de 20 de novembro de 2003 (2003, 20 novembro). Regulamenta o procedimento para identificação, reconhecimento, delimitação, demarcação e titulação das terras ocupadas por remanescentes das comunidades dos quilombos de que trata o art. 68 do Ato das Disposiçôes Constitucionais Transitórias. Diário Oficial da Uniāo, 21 nov. 2003, p. 4. 
Dias, A. F. L. (2018, janeiro-junho). A democracia como vítima do golpe tragicômico de 2016 no Brasil. Argumentos: Revista de Filosofia, 19, 6272. Recuperado a partir de http://periodicos.ufc.br/argumentos/article/ view/32018/72329

Eco, U. (1995, June). Ur-Fascism. The New York Review of Books, 22. Recuperado a partir de https://www.nybooks.com/articles/1856

Foucault, M. (1993). O anti-Édipo: uma introdução à vida não fascista. Cadernos de Subjetividade, 1(1), 197-200.

Furlan, V. (2017). Psicologia e políticas de direitos: percursos de uma relação. Psicologia, Ciência e Profissão, 37(núm. especial), 91-102.

Garcez, F. T. C., Martins, L. H. C., Guilherme, I. M., \& Batista, K. S. A. (2019). $\mathrm{O}$ avançar da agenda conservadora e o fascismo latente no Brasil. Revista Uniabeu, 12(30), 161-174.

Harvey, D. (2012). Ocuppy: movimentos de protesto que tomaram as ruas. São Paulo: Boitempo.

Hobsbawm, E. (2007). Globalização, democracia e terrorismo. São Paulo: Companhia das Letras.

Hur, D. U. (2012). Políticas da Psicologia: histórias e práticas das associações profissionais (CRP e SPESP) de São Paulo, entre a ditadura e a redemocratização do país. Psicologia USP, 23(1), 69-90.

Hur, D. U. (2018). Psicologia, política e esquizoanálise. Campinas: Alínea.

Hur, D. U., \& Lacerda Júnior, F. (2017). Psicologia e Democracia: da ditadura civil-militar às lutas pela democratização do presente. Psicologia, Ciência e Profissão, 37(núm. especial), 3-10.

Iasi, M. L. (2009). Prefácio. Nosso guia na floresta de papel: o artífice da palavra clara. In L. Konder (2009), Introdução ao Fascismo. (pp. 9-20). São Paulo: Expressão Popular.

Konder, L. (2009). Introdução ao fascismo. São Paulo: Expressão Popular.

Lei Federal n.o 4.119, de 27 de agosto de 1962 (1962, 27 agosto). Parte vetada pelo Presidente da República e mantida pelo Congresso Nacional, do Projeto que se transformou na Lei no 4.119, de 27 de agosto de 1962 (que dispóe sobre 
os cursos de formação em Psicologia e regulamenta a profissão de Psicologista. Diário Oficial da Uniāo, 5 set. 1962, p. 9253.

Mbembe, A. (2018). Necropolítica. São Paulo: N-1.

Paxton, R. (2007). Anatomia do fascismo. São Paulo: Paz e Terra.

Prado Filho, K., \& Trisotto, S. (2017). A Psicologia como disciplina da norma nos escritos de M. Foucault. Revista Aulas Dossiê Foucault, 1(3), 1-14.

Resolução CFP n.o 1, de 22 de março de 1999 (1999, 22 março). Estabelece normas de atuação para os psicólogos em relação à questão da orientação sexual. Brasília: Conselho Federal de Psicologia. Recuperado a partir de https://atosoficiais.com.br/cfp/resolucao-do-exercicio-profissional-n-1-1999estabelece-normas-de-atuacao-para-os-psicologos-em-relacao-a-questao-daorientacao-sexual?origin $=$ instituicao $\& \mathrm{q}=1$

Resolução CFP n.o 1, de 29 de janeiro de 2018 (2018, 29 janeiro). Estabelece normas de atuação para as psicólogas e os psicólogos em relação às pessoas transexuais e travestis. Brasília: Conselho Federal de Psicologia. Recuperado a partir de https://atosoficiais.com.br/cfp/resolucao-do-exercicio-profissional-n1-2018-estabelece-normas-de-atuacao-para-as-psicologas-e-os-psicologos-emrelacao-as-pessoas-transexuais-e-travestis?origin=instituicao\&q=1

Rolnik, S. (2018). Esferas da insurreição: notas para uma vida não cafetinada. São Paulo: N-1 Edições.

Rose, N. (2011). Inventando nossos selfs: psicologia, poder e subjetividade. Rio de Janeiro: Vozes.

V-Dem Institute (2019). Democracy facing global challenges. In V-Dem Annual Democracy Report. Gothenburg: University of Gothenburg. 